\title{
SIMULAÇÕES COMPUTACIONAIS E FERRAMENTAS DE MODELIZAÇÃO EM EDUCAÇÃO QUÍMICA: UMA REVISÃO DE LITERATURA PUBLICADA
}

\author{
Angela A. Ribeiro* \\ Centro de Ciências Naturais e Exatas, Universidade Luterana do Brasil, Rua Miguel Tostes, 101, 92420-280 Canoas - RS \\ Ileana M. Greca \\ Instituto de Física, Universidade Federal do Rio Grande do Sul, Campus do Vale, 91501-170 Porto Alegre - RS
}

Recebido em 14/8/02; aceito em 14/11/02

\begin{abstract}
COMPUTER SIMULATIONS AND MODELING TOOLS IN CHEMICAL EDUCATION: A REVIEW OF PUBLISHED LITERATURE. This article presents a review of published literature concerning the use of computer simulations and modeling tools in Chemical Education. The findings about the possibilities of their application in the Chemistry curriculum, their effective implementation, the teaching methods involved, the research methodology and also the instruments of evaluation that were used and their results were described and analyzed. The need to develop adequate theory support to educators who want to start using this new technology in their Chemistry classes became evident along the research, as well as the lack of development of model perception among Chemistry educators and learners.
\end{abstract}

Keywords: chemical education; modeling tools; literature review.

\section{INTRODUÇÃO}

Nas últimas cinco décadas, a aliança feita entre Ciência e Tecnologia provocou grandes mudanças que possibilitaram a aceleração do desenvolvimento tanto de uma, quanto de outra ${ }^{1}$. De 1989 para cá, o avanço da tecnologia teve um ritmo surpreendentemente mais acelerado, ocupando espaços cada vez maiores em nossa vida cotidiana, não se podendo hoje conceber muitas de nossas rotinas e hábitos sem a atual tecnologia. Assim, não poderia a tecnologia passar desapercebida por um setor bastante relevante da nossa realidade: a Educação. A vinculação das novas tecnologias e da informática à Educação gerou posturas divergentes. Alguns pesquisadores, sobretudo durante as décadas de 1970 e 1980, apresentaram-se extremamente otimistas quanto ao seu uso, atribuindo à tecnologia a possibilidade de solução dos problemas educacionais ${ }^{2}$, ao parecer considera que, por simples voluntarismo, poderiam se resolver todas as situações que se apresentassem desfavoráveis a tal empreendimento. Esta postura tem sido criticada pela ausência de um aprofundamento em questões fundamentais, como todas as condições necessárias para um ganho efetivo com o uso das novas tecnologias. Outros pesquisadores, no extremo oposto, caíram em ceticismo, apoiando sua descrença em questões reais, como a precariedade material do sistema educacional, ou filosóficas, alegando que o computador nos conduziria inevitavelmente a um tecnicismo desumanizador. Recentemente, educadores e pesquisadores começaram a despertar para uma nova postura sobre o assunto, que se caracteriza por uma visão crítica diante da tecnologia, porém não cética, numa compreensão do contexto histórico, em que as condições políticas, econômicas e sociais são consideradas variáveis importantes do processo ensino/aprendizagem, visão esta classificada como pró-ativa ${ }^{3}$. Nesta, considera-se conjuntamente o uso de tecnologias, os métodos empregados e a redistribuição de papéis no contexto educacional ${ }^{2}$.

Fazendo um pouco de história, cabe lembrar que nos anos 80 , estágio inicial do uso de computadores na área de Educação para o ensino fundamental e médio, sobretudo nas escolas americanas, havia

*e-mail: angella@via-rs.net uma visão de instrução auxiliada por computador, "Computer Aided Instruction" - CAI, na qual o computador, em grande medida, ditava a aprendizagem, perspectiva com a qual já eram usados desde a década de 1960 no ensino universitário ${ }^{4}$. Esta forma de utilizar o computador estava muito apoiada na chamada instrução programada da década de 70, embasada em uma postura condutista. Porém, com o tempo, o computador passou a ser usado como um instrumento para a aprendizagem, sob o controle do aluno, a aprendizagem assistida por computador, "Computer Assisted Learning" - CAL ${ }^{5}$ : nesta perspectiva, tenta-se utilizar o computador de forma integrada, dentro de uma perspectiva construtivista da aprendizagem. Passa-se a considerar que os recursos tecnológicos devem ser adaptados ao estilo de aprendizagem dos alunos, num contexto que se preocupe com o método e com a abordagem educacional. Ou seja, a utilização de computadores em sala de aula requer não só seu uso de maneira adequada, mas uma integração conveniente com o enfoque educacional adotado: a tecnologia deve se adequar à Educação e não o contrário ${ }^{4,6,7}$.

Ainda levando estes pontos em consideração, aparentemente as ferramentas computacionais permitem a exploração de novas estratégias de ensino. Esquembre ${ }^{7}$, por exemplo, ressalta que as novas tecnologias proporcionam oportunidades para a criação de ambientes de aprendizagem, que ultrapassam as possibilidades das ferramentas antigas (livros, quadro...), trazendo problemas do mundo real para a sala de aula, tornando o currículo mais interessante, bem como propiciam suporte e ferramentas para o aumento da aprendizagem, originam oportunidades para "feedback", reflexão e revisão, constroem comunidades locais e globais, que incluem professores, administradores, alunos, pais e cientistas e expandem oportunidades para o aprendizado do professor. Em particular, para a educação em ciências, passou-se a considerar que, assim como o computador vem alterando a forma da construção da Ciência, mudando as relações entre teoria e experimentação, pode transformar a forma de ensino, por se tratar de um instrumento que possibilita aos estudantes a compreensão da relação causal entre as variáveis, com o isolamento e a manipulação de um parâmetro por vez e o teste de hipóteses alternativas, oportunizando aos alunos a participação em atividades de modelização ${ }^{8}$. 
As potencialidades do uso das novas tecnologias para a educação podem ser vistas a partir da variedade de usos possíveis. Esquembre ${ }^{7}$ classifica os "softwares" educacionais em Física, de acordo com os princípios de seu uso, em:

- ferramentas para aquisição e manipulação de dados;

- multimídia: baseada em conceitos de hipermídia, apresentando as informações de forma estruturada e geralmente gráfica;

- micromundos e simulações: os primeiros consistem em programas muito completos que implementam a simulação de uma vasta gama de processos e leis, enquanto as últimas são programas menores, com modelos de um sistema ou processo voltado para a sua visualização;

- ferramentas de modelização: programas que permitem que o usuário construa a sua própria simulação;

- ferramentas da Web: exploram a capacidade de intercomunicação do computador, fazendo uso de todos os programas anteriormente mencionados.

Vieira ${ }^{4}$, de outro modo, classificou os "softwares" educacionais para Educação Química - encontrados entre 1978 e 1994 no periódico Journal of Chemical Education - em 12 categorias:

- Aquisição de dados e análise de experimentos: esses programas podem fazer a organização e a análise dos dados do experimento, traçando gráficos e apresentando várias tabelas com estatísticas diferentes, conforme a necessidade.

- Base de dados (BD) simples: conjunto organizado de dados com uma lógica que permite rápido acesso, recuperação e atualização por meio eletrônico.

- $\quad \mathrm{BD} /$ Modelagem: apresentam características comuns aos de base de dados simples, isto é, utilizam os mesmos recursos de acesso e gerenciamento de dados e das modelagens, que executam normalmente uma grande quantidade de cálculos matemáticos.

- BD / Hipertexto e/ou Multimídia: as bases de dados já existentes para PC's com os recursos de som e imagens coloridas.

- Cálculo computacional: resolvem equações matemáticas dos mais diferentes tipos, realizam inúmeros cálculos, como por exemplo, os relativos a $\mathrm{pH}$, propriedades termodinâmicas, equilíbrio químico, análises qualitativas e quantitativas, etc, propiciam uma ponte entre o que se tem, por exemplo, equações e dados experimentais, e o que se deseja, geralmente informações e resultados estruturados na forma de tabelas e gráficos variados.

- Exercício e prática: apresentando um conjunto de exercícios ou questões para o aluno resolver.

- Jogo educacional: programas de jogos, que permitem que o aluno desenvolva a habilidade de testar hipóteses, funcionando como se fosse um constante desafio à sua imaginação e criatividade.

- Produção de gráficos e caracteres especiais: muito úteis no ensino de certos conteúdos de química.

- Simulação: programas que trazem modelos de um sistema ou processo.

- Sistema especialista: programas de grande complexidade e custo, usados em diagnósticos e pesquisas.

- Tutorial: programa que "ensina" ao aluno uma determinada área de conhecimento, tendo a vantagem de ser mais dinâmico e animado (sons e imagens) que um livro texto.

- Outros: tipos de programas que, por sua especificidade e pequena quantidade, não puderam constituir uma classificação específica. Como se pode observar, as possibilidades de uso destas novas tecnologias são muito grandes, têm evoluído e se modificado. $\mathrm{Na}$ Química, em particular, nos últimos dez anos houve um verdadeiro salto na produção de "softwares" para a educação. Pode-se observar isto a partir de 131 revisões destes tipos de programa, feitas por professores universitários, publicadas "on line" ${ }^{9}$, entre 1992 e 1999. A partir destas, pode-se constatar que, no período de 92 a 94, a grande maioria dos programas destinavam-se a pesquisadores - lembremos que o uso de computadores em Química surgiu primeiramente a serviço da pesquisa em Físico-Química, para depois ser adotado pela Química Orgânica e Inorgânica ${ }^{10}$ - ou para preparo de material de professores. Nestes anos, encontram-se poucas simulações de qualidade para serem usadas por alunos. Algumas delas apresentavam certos problemas para o manuseio, especialmente com o armazenamento de dados e acuidade de informações, apresentando, às vezes, algumas inconsistências conceituais, por exemplo, ao arranjar determinado átomo em uma molécula o usuário não tinha condições de obter dados sobre a mudança da carga do mesmo depois da estruturação da molécula. A partir de 94, alguns "softwares" já existentes começaram a ser adaptados pelos "designers" para o ensino. Em 1995, surgiram comentários freqüentes sobre o uso sistemático de "softwares" para o ensino: os professores poderiam usá-los efetivamente em sala de aula e muitos programas surgiram como substitutivos do livro-texto. Em 96, apareceram os primeiros comentários sobre o uso de programas para a aprendizagem, e não para o ensino, encontrando-se em manual de instruções levantamento das habilidades necessárias para a Educação Química, com falta de unanimidade entre os autores. A partir de 97, aparecem, em grande número, "softwares" gratuitos na Internet e, entre os revisados, há predominância de hipertextos. Em 99, surge a idéia do aluno responsável por sua aprendizagem - alguns revisores analisam o "software" também segundo a capacidade de proporcionar ou não estudo independente (auto-aprendizagem).

Em vista do amplo material disponível, o objetivo da presente pesquisa é fazer um levantamento e análise crítica de resultados de pesquisa obtidos a partir do uso de simulações e de ferramentas de modelização na educação em química, buscando-se, assim, averiguar as possibilidades de utilização no currículo, a implementação, as estratégias didáticas utilizadas, a metodologia, os resultados e sua validade, bem como o enfoque educacional vinculado ao uso das ferramentas analisadas. Procurou-se ainda analisar os instrumentos de avaliação utilizados para medir a eficácia destas ferramentas no aprimoramento do ensino de Química, numa tentativa de fazer um paralelo entre o avanço das pesquisas sobre "softwares" educacionais produzidos e lançados no mercado e a efetividade destes na prática pedagógica.

Os artigos analisados surgiram a partir de consulta feita ao banco de dados do ERIC, com a seleção de textos relacionados ao assunto e publicados nos últimos dez anos. Os textos estudados são provenientes das seguintes publicações: Chemistry Education: Research and Practice in Europe, Computer Physics Communications, Computers and Education, Education in Chemistry, Educational and Training Technology International, Educational Technology and Research, Ensaio - Pesquisa em Educação e Ciências, International Journal of Science Education, Journal of Chemical Education, Journal of Educational Technology Systems, Journal of Research in Science Teaching, Química Nova, Review of Educational Research, Review of Research in Science Education e The Chemical Educator. Foram consultados também “sites” específicos de Química e Educação Química.

Antes de avançar, é importante justificar porque nossa revisão centrou-se exclusivamente no uso de simulações e de ferramentas de modelização. Um dos principais objetivos dos pesquisadores de Educação Química nos últimos anos tem sido buscar a melhoria da compreensão conceitual dos alunos ${ }^{11}$. Os esforços incluem a identificação dos enganos mais comuns dos alunos - suas dificuldades em problemas nos quais seja necessário pensar a nível molecular e a criação de métodos de acesso e mensuração da compreensão conceitual, a criação e implementação de novas formas de instrução química, destinados a promover justamente a melhoria da compreensão conceitual ${ }^{12}$. 
A grande dificuldade em oportunizar aos alunos o desenvolvimento da compreensão conceitual em Química reside no fato de que, apesar de encontrarmos, às vezes, estudos de fenômenos macroscópicos, a maior parte do universo dos fenômenos estudados nesta ciência aborda fenômenos que ocorrem a nível microscópico, o que dificulta bastante a aquisição da compreensão dos conceitos, uma vez que, neste nível, faltaria aos alunos o contato com informações sensoriais. Além desta dificuldade, a Química é uma ciência essencialmente simbólica, isto é, trabalha com símbolos para representar elementos e fenômenos, e o aluno, além de ter que conhecer tais símbolos, ainda deve ter a capacidade de transformar determinada forma de representação em outra equivalente, de maneira mais apropriada ${ }^{11}$. Ou seja, os estudantes deveriam desenvolver uma competência representativa, justamente uma das capacidades que diferenciam o nível de conhecimento dos novatos do nível dos especialistas ${ }^{13}$.

Para explicar e explorar fenômenos, processos e idéias abstra$\operatorname{tas}^{14}$, bem como para proporcionar aos alunos o desenvolvimento da capacidade de representação em seus distintos níveis e auxiliá-los na competência representativa, os pesquisadores têm sugerido várias abordagens pedagógicas, dentre as quais tem se destacado, nos últimos anos, o uso de simulações computacionais e de ferramentas de modelização ${ }^{11}$. Há décadas atrás, os únicos meios disponíveis para os educadores consistiam em representações pictóricas, esquemáticas ou modelos estáticos. Com o advento do desenvolvimento tecnológico, atualmente os profissionais de Educação Química já podem dispor de ferramentas que proporcionam visualização de representações de modelos dinâmicos. Neste sentido, os "softwares" de simulação e as ferramentas de modelização, podem ser de grande utilidade para que os educadores consigam proporcionar condições aos alunos de, a partir da modelização de determinado fenômeno, desenvolverem a compreensão conceitual dos estudos desenvolvidos, não mais fazendo o uso mecânico dos conceitos que envolvem os fenômenos estudados ${ }^{15}$.

\section{Simulações e ferramentas de modelização na Educação Química}

Simulações computacionais são programas que contêm um modelo de um sistema ou processo ${ }^{16}$. As simulações podem ser classificadas, de uma forma ampla, em conceituais ou operacionais. As primeiras apresentam princípios, conceitos e fatos relacionados ao(s) evento(s) simulado(s), como a simulação da estruturação de uma molécula, da mudança de temperatura de determinada substância ou da alteração da pressão exercida sobre alguma amostra. As últimas incluem sequiências de operações e procedimentos que podem ser aplicados ao(s) sistema(s) simulado(s), como por exemplo, as simulações pré-laboratoriais ou laboratoriais propriamente ditas, que permitem que o aluno exercite a execução correta dos procedimentos em um laboratório, como simular a esterilização e manuseio de equipamentos ao realizar determinado experimento ${ }^{17}$. Em uma simulação, o comportamento deve representar o funcionamento do sistema real, segundo as teorias ou modelos que o descrevem, ou seja, são representações de um sistema que a teoria supõe ser real, que possibilitam interações sem as limitações ou perigos que o sistema real possa ter ${ }^{6}$. Neste tipo de "software", existe um modelo subjacente pré-determinado, construído pelo pesquisador ou professor, ao qual o aluno não tem acesso, o que significa que este não tem condições de questioná-lo, discuti-lo ou modificá-1o ${ }^{18}$. Através deste tipo de programa, o aluno é capaz de visualizar eventos que acontecem a nível microscópico para construir posteriormente um modelo mental do fenômeno e, a partir deste, fazer previsões ${ }^{19}$. O uso de simulações, porém, não garante por si só a compreensão conceitual destes diferentes fenômenos microscópicos e de sua conseqüente manifestação a nível macroscópico ${ }^{6}$.
Por outro lado, ferramentas de modelização são programas em que o usuário desenvolve sua própria simulação computacional, beneficiando-se das mesmas vantagens desta, com a possibilidade adicional de criar a oportunidade de explicitar suas próprias concepções ${ }^{7,8}$. Através de ferramentas deste tipo de programa, os alunos podem descrever relações entre conceitos, aplicar os modelos construídos e comparar os resultados obtidos com o conhecimento que é aceito pela comunidade científica ou com experimentos laboratoriais. Este procedimento de confrontação permite ao educando perceber seus enganos, fazer uma reflexão crítica sobre o modelo criado e operacionalizar as mudanças necessárias, fazendo a transposição dos seus conceitos intuitivos para concepções mais sistematizadas, rumo a um conhecimento mais axiomático, o que é chamado por Penner ${ }^{18}$, de desenvolvimento de um modelo sintético. Segundo este autor, há ainda, surpreendentemente, poucas pesquisas relativas à exploração desta ferramenta no contexto educacional. De fato, na busca sistemática realizada para esta pesquisa, não encontramos nenhum artigo de relato de uso, em Educação Química, de ferramentas de modelização feito por alunos. Mesmo nas revisões analisadas, vários programas de simulação foram descritos como "softwares" de modelização, apresentando, porém, modelos prontos subjacentes, sem oportunizar mudanças do modelo, não se adequando à definição acima, enquanto os "softwares" de autoria (aqueles em que o usuário constrói seu próprio multimídia) são sempre descritos como se fossem destinados a professores ou pesquisadores.

\section{Currículo de Química e ferramentas computacionais}

Nesta seção será abordada a possibilidade de uso das simulações computacionais no currículo de Química, tanto as operacionais quanto as conceituais. Ou seja, retrataremos as várias áreas da Química, às quais são aplicáveis os "softwares" de simulação disponíveis, fazendo-se uma breve exposição dos argumentos e justificativas encontrados que fundamentam as vantagens do uso de simulações, quer conceituais, quer operacionais. Ainda será abordada a possibilidade de uso de simulações para a integração entre Química e outras disciplinas, a transversalidade curricular.

Em termos de simulações operacionais, apesar de haver a argumentação de que o custo de sua aquisição constitui uma barreira para a implementação efetiva, análises feitas por professores universitários concluíram que o orçamento para implementações de simulações laboratoriais virtuais pode ficar aquém do que o necessário para o uso constante e manutenção de laboratórios reais ${ }^{18,19}$, oportunizando aos alunos maior disponibilidade de focar a atenção no experimento em si, uma vez que não há risco de danificação de materiais e equipamentos, nem a tensão gerada para o preparo cuidadoso do experimento ${ }^{22,23}$, com maior rapidez e precisão na obtenção de resultados, tornando-os melhor qualificados para o mundo no qual viverão e trabalharão. Isso inclui o trabalho prático com instrumentação para espectroscopia, técnicas de separação, métodos eletroquímicos, bem como a aquisição e análise de dados computadorizados $^{20}$.

Num escopo de 74 simulações, encontramos a descrição de 7 "softwares" de simulações operacionais ${ }^{9,20,21,24}$ : 1 específico para Química Inorgânica, 1 para Química Orgânica, 1 para Físico-Química, 2 para Química Geral, sendo os outros 2 úteis para as 4 áreas já citadas, com 1 deles permitindo ainda o uso específico para Bioquímica e Química Analítica.

Em relação a simulações conceituais, a pesquisa mostra que visualizações podem ajudar na compreensão conceitual ${ }^{25}$, como já fora indicado na Introdução. Neste campo, as modelizações computacionais em Química são fundamentais, por se tratar de uma Ciência que se constrói a partir da exploração do invisível e intocável, 
constituindo um estudo inerentemente simbólico e representativo ${ }^{13}$. Convém salientar que o termo "modelizações" aqui empregado não se refere às ferramentas de modelização, como foram definidas na Introdução, mas relaciona-se à utilização de modelos, para a criação de representações mentais e construção da compreensão conceitual.

Em se tratando de simulações conceituais, apareceram as descrições de 67 simulações computacionais distintas 2 , 6, 9, 11-14, 22, 25-38. Muitas delas, de forma análoga às operacionais, possuem a possibilidade de utilização em mais de uma área da Química. Os resultados encontram-se registrados na Tabela 1.

Tabela 1. Possibilidades de aplicação das simulações analisadas ao currículo de Química

\begin{tabular}{lcc}
\hline Área de Estudo & $\begin{array}{c}\text { 67 Simulações } \\
\text { Conceituais }\end{array}$ & $\begin{array}{c}\text { 07 Simulações } \\
\text { Operacionais }\end{array}$ \\
\hline Analítica & 07 & 01 \\
Bioquímica & 17 & 01 \\
Cristalografia & 07 & \\
Farmacologia & 01 & 03 \\
Físico-Química & 20 & 04 \\
Geral & 41 & 03 \\
Inorgânica & 24 & 03 \\
Orgânica & 27 & \\
Organometálica & 01 & \\
Polímeros & 11 & \\
Teórica & 14 & \\
\hline
\end{tabular}

Uma possibilidade pouco explorada na prática pela Educação Química, em vistas da revisão que efetuamos, é a integração, a partir do uso de ferramentas computacionais, entre diferentes disciplinas, como a Geologia, a Física, a Biologia, com a Química - a transversalidade curricular ou interdisciplinaridade - com o intuito de oportunizar ao aluno o desenvolvimento da conexão entre a visão particulista e a visão global do mundo, ou seja, como o comportamento particulista da matéria se reflete nas propriedades visíveis da mesma. Neste sentido encontramos apenas um artigo que descreve o trabalho realizado, com o intuito de integrar a Química com Geologia, em que há a descrição de 4 sessões laboratoriais, 2 realizadas conjuntamente por professores das duas disciplinas e 2 coordenadas exclusivamente por professores de Geologia. Neste relato, há destacada ênfase na importância do uso de simulações para possibilitar aos alunos a compreensão da inter-relação entre o comportamento particulista da matéria e sua implicação a nível macroscópico, o que é basicamente o universo de trabalho da Geologia ${ }^{22}$.

Como se pode verificar, as possibilidades de utilização de simulações no currículo de Química são bastante variadas e apresentam grandes perspectivas de uma exploração maior no futuro.

Nada se pode afirmar a respeito do uso efetivo de ferramentas de modelização em Educação Química, uma vez que não encontramos nenhum trabalho publicado que relate sua utilização. Porém, por argumentos já indicados em seção anterior deste trabalho, temos a convicção de que esta é uma área que vale ser investigada.
Gostaríamos de ressaltar que, embora a idéia de modelos e modelização subjaza à representação de um fenômeno, segundo as leis e princípios que o descrevem, através da criação ou uso de modelos, requerendo não só a compreensão conceitual do fenômeno em si, mas também de suas demais implicações com outros fenômenos e fatos, o que vai além da mera memorização de conceitos e mecanização de estratégias de solução de problemas, a noção da percepção de modelos e de suas diferentes naturezas por parte de alunos e professores, a partir do uso destas ferramentas, não tem sido objeto de estudo, uma vez que só encontramos um trabalho publicado neste sentido, realizado por Barnea e Dori ${ }^{14}$. Neste trabalho, os autores constataram que nem o grupo de professores nem o grupo de alunos tinham esta noção desenvolvida, após avaliação inicial, implementando a seguir um trabalho com o objetivo do desenvolvimento da percepção dos diferentes tipos de modelos (modelos mentais, modelos expressos, modelos consensuais e modelos de ensino) e de seu papel para o aprendizado e desenvolvimento do conhecimento científico (no caso, químico).

\section{Implementações em sala de aula de Química}

No universo das referências apresentadas no final deste artigo, foram encontradas apenas 16 descrições de implementações efetivas de simulações em sala de aula $2,5,10-12,14,20,22,24,25,28,30,32,33,35,37$ : 9 nos Estados Unidos, 2 no Reino Unido, 2 na Nova Zelândia, 1 na Austrália, 1 no Japão e 1 em Israel.

A maioria do material restante apenas descreve o possível uso a ser feito pelo "software", sugerindo exercícios, atividades ressaltando conceitos químicos e relações conceituais. Alguns artigos mencionam o uso de simulações ao descrever as vantagens da Química Computacional, mas não detalham a implementação, sendo, assim, descartados para análise nesta seção.

Artigos como o de Kozma e Russell ${ }^{13}$, que descrevem a diferença entre o conhecimento de novatos e especialistas em Química, não foram computados como implementação, uma vez que não envolveram a rotina de uma sala de aula.

Das 16 implementações documentadas, 13 ocorreram em cursos universitários, sendo $12 \mathrm{em}$ cadeiras de Química e apenas $1 \mathrm{em}$ cadeira do curso de Geologia. As 3 restantes foram realizadas em escolas de nível médio.

Dos 16 relatos, 7 descrevem o uso sistemático contínuo, envolvendo todos os alunos matriculados em cursos universitários. Nos 9 restantes, temos descrições pontuais do uso de simulações em sala de aula, que variam de $6 \mathrm{~h}$ a 1 semestre. Estes dados aparecem sistematizados na Tabela 2.

É de certa forma paradoxal verificar que, diante de tanto desenvolvimento de tecnologia educacional voltada para Química, a quantidade de relatos sobre implementação efetiva destas ferramentas seja em número tão reduzido, sendo igualmente escassa a quantidade de artigos voltados à pesquisa sobre o uso desta tecnologia, com vistas a proporcionar embasamento teórico e técnico para que os professores, sentindo-se seguros, trabalhem em sua prática pedagógica.

É possível que se possa atribuir a subutilização desta tecnologia educacional à falta de preparo adequado de profissionais da educa-

Tabela 2. Relatos de implementações de simulações encontrados

\begin{tabular}{lcccc}
\hline Nível & $\mathrm{N}^{\mathrm{o}}$ & $\begin{array}{c}\text { Uso efetivo na } \\
\text { prática pedagógica }\end{array}$ & $\begin{array}{c}\text { Uso para fins } \\
\text { investigativos }\end{array}$ & $\begin{array}{c}\text { Uso Sistemático } \\
\text { Sim }\end{array}$ \\
\hline Universitário & 13 & 07 & 06 & 07 \\
Médio & 03 & 01 & 02 & 06 \\
Total & 16 & 08 & 08 & 03 \\
\hline
\end{tabular}


Tabela 3. Estratégias utilizadas na implementação efetiva de ferramentas de simulação na prática pedagógica

\begin{tabular}{|c|c|c|c|c|c|c|c|c|}
\hline Tipo de Trabalho & $\begin{array}{c}\mathrm{N}^{\mathrm{o}} \text { de } \\
\text { Relatos }\end{array}$ & $\begin{array}{c}\text { Enfase na } \\
\text { Escrita }\end{array}$ & $\begin{array}{l}\text { Ensaio } \\
\text { e Erro }\end{array}$ & $\begin{array}{l}\text { Interação } \\
\text { muito } \\
\text { restrita }\end{array}$ & $\begin{array}{c}\text { Sessão } \\
\text { Teórica + } \\
\text { Exercícios }\end{array}$ & $\begin{array}{l}\text { Método } \\
\text { Socrático c/ } \\
\text { Questões } \\
\text { Abertas }\end{array}$ & $\begin{array}{c}\text { Discussão c/ } \\
\text { Questões } \\
\text { Diretivas }\end{array}$ & $\begin{array}{c}\text { Projetos } \\
\text { de pesquisa }\end{array}$ \\
\hline Não Apresenta & 03 & - & - & - & - & - & - & - \\
\hline Trabalho Individualizado & 07 & - & 01 & 03 & - & 01 & 01 & \\
\hline Trabalho em Grupos & 05 & - & - & - & 01 & - & 02 & 02 \\
\hline Trabalho Interdisciplinar & 01 & 01 & - & & - & - & - & \\
\hline Total & 16 & 01 & 01 & 03 & 01 & 01 & 03 & 02 \\
\hline
\end{tabular}

ção para trabalhar com este novo tipo de instrumento que surgiu ao longo dos últimos anos ${ }^{4,6}$.Ou seja, o desenvolvimento da projeção de "softwares" para Educação Química não estaria sendo acompanhado por uma formação adequada para os professores, que não encontram com facilidade suporte teórico e técnico que lhes propicie segurança para desenvolver um trabalho pedagógico com este tipo de ferramenta. Obviamente, devemos ter em mente que o critério utilizado nesta pesquisa - de ocorrência de artigos nas revistas pesquisadas - não está levando em consideração o possível uso destas ferramentas em casos não documentados. No entanto, se sabe que a implementação de novas metodologias em sala de aula está usualmente vinculada a projetos de pesquisa e termina, portanto, sendo publicada. Muito raramente professores isolados introduzem práticas inovadoras de novas metodologias nas suas aulas.

\section{Metodologias didáticas utilizadas}

Procuramos verificar as metodologias didáticas utilizadas tanto nos relatos de uso efetivo de ferramentas de simulação computacionais na prática pedagógica ${ }^{2,5,10,20,22,28,30,32}$ quanto nos trabalhos de implementações a partir de pesquisas ${ }^{11,12,14,24,25,33,35,37}$, que aparecem descritas na Tabela 3.

Como se pode constatar na Tabela 3, não encontramos uniformidade entre os tipos de metodologias didáticas empregadas. Os "softwares" têm sido usados tanto individualmente quanto em grupos.

Analisando em particular os trabalhos de pesquisa, em 3 deles foi adotado o trabalho em pequenos grupos. Em uma das pesquisas os alunos foram estimulados a desenvolver um projeto de pesquisa, sendo a ferramenta de simulação utilizada entre a $2^{\mathrm{a}}$ e a $4^{\mathrm{a}}$ semanas do projeto. Já em outro relato, o enfoque é sobre a aprendizagem por descoberta guiada, com ampla interatividade com o "software" na busca de solução de problemas. E na terceira pesquisa que adotou trabalhos em pequenos grupos, foi implementada a prática da discussão para o desenvolvimento da percepção de modelos, de seus tipos e papéis, primeiramente com grupo de professores, que trabalharam com "softwares" de autoria, e posteriormente com o grupo de alunos, que utilizaram as simulações criadas pelos professores. As demais 5 pesquisas encontradas optaram por adotar um trabalho individualizado para o aluno. Uma delas adotou simulações prontas, em que o aluno não poderia interagir com o computador (anima- ções). Em 3 relatos, a interação com o computador é bastante restrita e limitada. Houve ainda um trabalho fundamentado em conceitos ausubelianos, no qual os alunos deveriam, individualmente, execu$\operatorname{tar} 4$ tarefas distintas, uma delas envolvendo simulação no computador.

Embora a amostra seja muito pequena, parece que há uma tendência a incorporar o uso de simulações dentro de um contexto mais amplo, seja como complementação de aulas teóricas ou integrado em diferentes versões de "projetos de pesquisa" (perguntas abertas, projetos mais ou menos dirigidos, etc).

\section{Metodologias de pesquisa utilizadas}

Nesta seção, descreveremos as metodologias de pesquisa que têm sido utilizadas para abordar a questão da efetividade do uso destas ferramentas, juntamente com os resultados obtidos a partir da realização das mesmas ${ }^{11,12,14,24,25,33,35,37}$. As metodologias de pesquisa adotadas foram, assim como aconteceu com as didáticas utilizadas na prática pedagógica efetiva, bastante variadas.

Em 2 trabalhos, os pesquisadores optaram pelo uso de pré e póstestes, enquanto em 5 relatos houve preferência pela adoção de grupos de controle. Um dos artigos não menciona nenhuma das duas práticas indicadas, mas expressa claramente o desejo de que seu trabalho forneça suporte teórico para o uso de novas tecnologias em Educação Química.

Os resultados dos trabalhos investigativos foram obtidos a partir de instrumentos variados, que objetivaram a mensuração de dois tópicos distintos: o "software" como ferramenta educacional e a compreensão conceitual do usuário (Tabelas 4 e 5).

Em relação ao primeiro tópico, encontramos 4 trabalhos que se preocuparam em investigar a opinião do aluno quanto à facilidade de uso do "software", se este influenciou ou não a qualidade e o ritmo da aprendizagem, bem como as dificuldades encontradas e as

Tabela 4. Investigação em relação ao "software"

\begin{tabular}{lcc}
\hline Avaliadores & Alunos & Professores \\
\hline Questões Abertas & 02 & - \\
Lickert & 02 & - \\
Total & 04 & 01 \\
\hline
\end{tabular}

Tabela 5. Investigação da compreensão conceitual

\begin{tabular}{lcc}
\hline Instrumentos & $\begin{array}{c}\text { Compreensão Conceitual } \\
\text { (conceitos químicos) }\end{array}$ & $\begin{array}{c}\text { Compreensão Conceitual } \\
\text { (percepção de modelos) }\end{array}$ \\
\hline Testes ou trabalhos escritos & 05 & 01 \\
Testes ou trabalhos escritos c/ gravação e transcrição de entrevistas & 02 & - \\
Total & 07 & 01 \\
\hline
\end{tabular}


mudanças necessárias para um melhor aproveitamento do mesmo. Foram assim utilizados questionários abertos e do tipo Lickert. Os resultados obtidos mostram que a maioria dos alunos considerou que o uso dos "softwares" teve um papel importante na qualidade e na rapidez do aprendizado, mostrando-se satisfeitos com o uso dos mesmos.

Quanto ao segundo tópico, houve a preocupação em investigar dois tipos de compreensão conceitual. O primeiro deles, relativo ao conhecimento químico propriamente dito e encontrado em todos os trabalhos investigativos, buscou mensurar a compreensão do aluno a respeito dos fenômenos que ocorrem em nível de partículas (compreensão particulista) e a capacidade de representá-los adequadamente de diferentes maneiras (competência representativa), quer na forma de questões abertas, quer na forma de resolução de problemas e com instrumentos bastante variados: teste para averiguar a compreensão da natureza da matéria, teste para mensurar o raciocínio lógico, trabalho em grupos, testes de múltipla escolha com enfoque na solução de problemas, questionário com questões abertas, gravação e transcrição do trabalho de alunos no computador ou de entrevista feita com alunos. De maneira geral, a maior dificuldade encontrada foi o desenvolvimento da competência representativa, uma vez que os resultados foram estatisticamente significativos em todos os trabalhos analisados no que diz respeito à compreensão particulista.

O segundo tipo de compreensão conceitual investigado foi o da percepção que os professores e alunos possuem a respeito de modelo, de suas diferentes naturezas (modelos mentais, modelos expressos, modelos consensuais e modelos de ensino), de seu papel e potencial de uso em Educação Química, realizado em um único estudo encontrado $^{14}$. Este demonstrou que nem o grupo de alunos, nem o de professores possuía, a princípio, esta percepção desenvolvida de forma adequada, implementando, após a constatação deste fato, um trabalho para desenvolver esta percepção em ambos os grupos. Como resultado deste trabalho, os pesquisadores constataram uma significativa melhora, em relação ao grupo de controle, no desempenho apresentado pelos alunos que trabalharam com a percepção de modelos.

É relevante destacar que, desde uma visão mais moderna da avaliação destas ferramentas, como as propostas por Whitelock ${ }^{39}$, as metodologias de pesquisa implementadas nos trabalhos revisados encontram-se bastante aquém do desejável. Assim, em relação aos pontos avaliados, nenhum dos trabalhos aborda questões relativas ao contexto (qual é a experiência com computadores, qual é a experiência com a tarefa, qual é a confiança dos estudantes com o sistema) ou as interações tanto com a máquina quanto entre os estudantes durante o uso das simulações (apenas 1 trabalho enfoca a interação entre os estudantes ${ }^{37}$ ). Também não se analisa a transferência da aprendizagem a partir de simulações para situações da vida real. Em relação aos instrumentos de coleta de dados que estão sendo usados ainda são muito restritos: apenas 2 trabalhos relatam o uso de filmagens ${ }^{11,35}$, enquanto nenhum menciona a utilização de diários de alunos, registro de ações coletadas pelo "software" ou de auto-avaliação. Portanto, este é um ponto relevante para ser levado em consideração em trabalhos com o objetivo de avaliar o uso de simulações.

\section{Enfoque educacional}

Um número relevante de artigos publicados em revistas como Journal of Chemical Education e Education in Chemistry enfoca o uso de novas tecnologias educacionais associado à aprendizagem por descoberta. Ou seja, através de condições proporcionadas por estas novas tecnologias, como "softwares" de simulação, os alunos poderiam isolar variáveis, estudar seus padrões e comportamentos e, a partir disto, encontrar as relações, os princípios e as leis que regem o fenômeno estudado.
Embora o uso de simulações e aprendizagem por descoberta apareçam correntemente associados na literatura, de Jong e van Joolingen ${ }^{16}$ observaram, a partir de uma revisão ampla da literatura, que, diante da constatação da inexistência das habilidades específicas necessárias aos alunos para a aprendizagem por descoberta (por exemplo, gerar hipóteses, projetar experimentos para testar estas hipóteses, interpretar os dados obtidos e administrar o processo de aprendizagem), houve a necessidade de adição de recursos de suporte aos programas para conduzir os alunos na descoberta de modelos. Três destes recursos foram destacados por estes autores como eficazes: a apresentação de informações e dados necessários durante o uso do programa, dentro de um contexto; a provisão de tarefas paralelas para os alunos (jogos, questões, exercícios) e, em caso de modelos complexos, medidas de estruturação de um esquema de progressão dentro do processo, ou seja, um planejamento de estratégias para guiar a progressão do usuário dentro do programa. Estas três medidas foram adotadas em um trabalho por nós encontrado ${ }^{37}$.

É interessante destacar que o uso destes recursos de suporte impede, de certa forma, a possibilidade de modelização errônea feita pelo aluno, ou seja, o aluno não teria muitas oportunidades de trabalhar com seus erros, uma questão que, como já indicamos, parece ser fundamental para a aprendizagem. De fato, este problema é comum a todas as simulações. As simulações, de forma geral, são programas que, trazendo um modelo pronto subjacente que procura evitar a modelização errada, apresentam informações, passadas de maneira tutorial, através da interação do usuário com o computador. Tal paradigma pedagógico é tido, erroneamente, como construtivista no sentido piagetiano, ou seja, capaz de propiciar a construção do conhecimento na "cabeça" do aluno, sendo, na verdade, um paradigma instrucionista ${ }^{3}$.

Segundo Valente ${ }^{3}$, a abordagem pela qual o aluno constrói, por intermédio do computador, seu próprio conhecimento, construindo primeiro um objeto de interesse (no caso, um modelo), para, a partir deste, organizar e testar hipóteses a respeito do objeto é adequada ao paradigma denominado por Papert, em 1986, de construcionista. Dentro deste paradigma, seriam úteis as ferramentas de modelização. Como já indicáramos, não encontramos nenhum trabalho neste sentido desenvolvido em Educação Química, embora ferramentas e implementações didáticas desta natureza já sejam utilizadas no ensino de Física ${ }^{6,40}$.

\section{CONSIDERAÇÕES FINAIS}

A cada dia que passa, o desenvolvimento científico e tecnológico torna os "softwares" educacionais mais acessíveis. Neste artigo foram abordadas as potenciais vantagens do uso de simulações conceituais para a Educação Química, por se tratar de uma ciência que se fundamenta em realidades invisíveis e, portanto, eminentemente simbólica, cujo escopo de trabalho é geralmente particulista, uma vez que trabalha basicamente com o comportamento de partículas. Foi mencionado que o uso destes recursos pode vir a ser de grande importância para o desenvolvimento de modelos conceituais e, de alguma forma, auxiliar no desenvolvimento da competência representativa. As simulações operacionais também apresentam grandes perspectivas para preparar o aluno para atuar no mundo em que ele efetivamente trabalhará. Parte destas potencialidades aparecem nas poucas pesquisas realizadas, que mostram uma melhoria no desenvolvimento conceitual e na competência representativa nos estudantes com o uso destas ferramentas.

Ficou clara, no decorrer da realização desta pesquisa, a necessidade de se realizar mais investigações e implementações que busquem desenvolver a percepção adequada de modelos e de sua aplicabilidade no currículo de Química, bem como desenvolver su- 
porte teórico e técnico quanto à metodologia e à avaliação, uma vez que a implementação destas novas tecnologias alterará inevitavelmente os papéis dentro de uma sala de aula e do contexto educacional. Kozma ${ }^{31}$ ressalta que os meios e os métodos juntos influenciam a aprendizagem, sugerindo que se deve transladar a visão de recursos computacionais como geradores de métodos para uma nova visão: a de que métodos e recursos juntos podem facilitar a construção do conhecimento e do senso crítico por parte dos alunos. No entanto, poucos são os trabalhos que se preocupam em enfocar e analisar estes aspectos. $\mathrm{O}$ único trabalho sobre modelos e modelizações realizado com professores para investigar a sua percepção de modelos e, a partir disso, implementar um conjunto de técnicas e procedimentos para expandir esta percepção, apontou como resultado, como já foi indicado, uma significativa melhora, em relação ao grupo de controle, no desempenho apresentado pelos alunos com os quais estes professores trabalharam posteriormente. Assim, pode-se sugerir que a construção de suporte teórico para fundamentar esse uso conjunto de "softwares" educacionais (dentre os quais simulações e ferramentas de modelização) com métodos adequados deva integrar o foco das pesquisas e trabalhos em Educação Química, de forma consistente e sistemática.

Resta também a sugestão da investigação do uso de ferramentas de modelização em Química, uma vez que estas se enquadram numa abordagem construcionista, exploram os modelos intuitivos dos usuários, levam-nos a testá-los e adaptá-los, proporcionam a sistematização de seu conhecimento, conduzindo-os a um conhecimento mais axiomático, característico do conhecimento construído por especialistas, e ainda satisfazem a visão de que o conhecimento científico é construído e mediado dentro de um contexto cultural ${ }^{18}$.

Um outro ponto pendente refere-se às avaliações realizadas nas pesquisas. As que nós encontramos parecem ainda superficiais, se levarmos em consideração todas as suas possibilidades, apresentando-se deveras distantes da mensuração do desenvolvimento do educando, do contexto, da tarefa e dos programas como um todo, de suas habilidades metacognitivas e preocupando-se predominantemente em medir a compreensão conceitual, bem como a competência representativa, como já indicado.

Antes de encerrarmos, gostaríamos de levantar alguns questionamentos que julgamos relevantes no atual estágio em que se encontra a Educação Química. Neste contexto que aponta para a utilização de modelos computacionais como um manancial de recursos preciosos para a Educação Química, que importância real tem sido dada ao professor? O professor que sofre pressões para o uso de novas tecnologias para o ensino de Química, sem ter tido acesso a suporte teórico e técnico para implementá-los, como salienta Waddick ${ }^{6}$. O professor que precisa mediar a ação aluno-computador, sob o ponto de vista computacional, pedagógico e psicológico. Aquele que precisa proporcionar ao aluno condições de desenvolver a percepção de modelos, de seu papel e de sua natureza, sem ter essa percepção bem desenvolvida e explicitada para si mesmo. E que, mesmo que, numa tentativa autodidata, buscasse recursos para se atualizar, não os encontraria facilmente ao alcance das mãos. Na pesquisa aqui apresentada somente um trabalho se preocupa com este lado da moeda. Segundo Vieira4, “um dos 'calcanhares de Aquiles' da Educação Química está exatamente na formação (às vezes inadequada) do professor". Há a urgente necessidade de se dedicar maior e melhor atenção à formação e permanente qualificação dos profissionais de Educação Química, fundamentada em estudos sistemáticos e consistentes que deveriam ser desenvolvidos. Caso contrário, não se pode cobrar destes profissionais uma atuação que produza resultados efetivos no desenvolvimento da compreensão conceitual dos alunos mediante o uso destas novas tecnologias. Aliás, faz-se urgentemente necessário que as licenciaturas utilizem, de forma sistemática, estes recursos para que os estudantes, futuros professores, adquiram segurança e naturalidade ao manuseá-los, tornando-se preparados para utilizar, avaliar ou criar este tipo de ferramentas em seu trabalho. A partir destas colocações, salientamos que o uso de novas tecnologias em Educação Científica (e Química) deve sempre considerar que tipo de aluno (e futuro profissional) se quer como produto desta educação. Esta preocupação deve pesar bastante tanto na escolha de ferramentas a serem utilizadas como na opção por estratégias facilitadoras de desenvolvimento de conhecimento. Tal postura exige do profissional permanente atualização, questionamento e aprimoramento de sua visão contextual e dos papéis que cada um desempenha ou pode vir a desempenhar neste contexto.

Para concluir, citaremos Anamelea de C. P. Luiz dos Santos 3 : “... não deve haver uma apologia cega aos instrumentos tecnológicos, o que resultaria numa formação que tenderia a perenizar a visão superficial desses recursos, encarados aí sem uma verdadeira base teórica e sem atentar, portanto, às verdadeiras questões envolvidas".

\section{AGRADECIMENTOS}

À FAPERGS, pelo suporte financeiro ao projeto.

\section{REFERÊNCIAS}

1. Bunge, M. Em Ciência e Desenvolvimento; Itatiaia: Belo Horizonte, Universidade de São Paulo, São Paulo, 1989, p. 32.

2. Roth, W.; Woszczyna, C.; Smith, G.; J. Res. Sci. Teaching 1996, 33, 995; Pence, H. E.; J. Educ. Technol. Syst. 1995-96, 24, 159.

3. Vários textos sobre Informática e Educação podem ser encontrados em: http://www.divertire.com.br/artigos/artigos.htm, acessada em Maio 2002.

4. Vieira, S. L.; Dissertação de Mestrado, Universidade Estadual de Campinas e Universidade Estadual do Centro-Oeste do Paraná, Brasil, 1997.

5. Waddick, J.; Educ. Train. Technol. Int. 1994, 31, 98.

6. Eichler, M.; Del Pino, J. C.; Quim. Nova 2000, 23, 835.

7. Esquembre, F.; Comput. Phys. Commun, no prelo.

8. Greca, I.; M. Projeto Integrado de Pesquisa - Modelização no Ensino de Física: Estudo do Processo de Formalização e de Estratégias Didáticas Facilitadoras, ULBRA, Canoas, 2002.

9. Avaliações para "softwares" educacionais em Química, organizadas cronologicamente em língua inglesa, podem ser encontradas em: http:// www.liv.ac.uk/ctichem/swrev.html, acessada em Maio 2002.

10. Gladwin, R. P.; Margerison, D.; Walker, S. M.; Computers Educ. 1992, 19 , 17.

11. Wu, H.; Krajcik, J. S.; Soloway, E.; J. Res. Sci. Teaching 2001, 38, 821.

12. Sanger, M. J.; Badger II, S. M.; J. Chem. Edu. 2001, 78, 1412.

13. Kozma, R. B.; Russell, J.; J. Res. Sci. Teaching 1997, 34, 949.

14. Barnea, N.; Dori, Y. J.; Chemical Education: Research and Practice in Europe 2000, 1, 109.

15. Embora as classificações apontadas por Esquembre ${ }^{7}$ e Vieira ${ }^{4}$ sejam bem semelhantes, podemos observar que, na última, não se menciona a classificação específica de ferramentas de modelização (mesmo na categoria "outros" não é encontrada a descrição de nenhum destes programas).

16. De Jong, T.; Van Joolingen, W. R.; Review of Educational Research 1998 , $68,179$.

17. Vieira ${ }^{4}$ ainda faz a distinção entre as simulações simples, que servem como preparação para o aluno antes que este tenha o experimento real no laboratório, e as com previsão, que apresentam maior interatividade com o usuário, permitindo-lhe chegar a conclusões e fazer previsões com a ajuda do próprio programa, não fazendo referências a simulações operacionais. Como efetivamente encontramos simulações operacionais, embora em número reduzido, analisadas por revisores e implementadas na prática pedagógica, adotaremos a classificação que distingue as conceituais das operacionais, considerando como pertencente ao segundo grupo todas as simulações que envolvem operações e procedimentos no modelo representado.

18. Penner, D. E.; Rev. Res. Sci. Educ. 2000-2001, 25, 01.

19. Greca, I. M.; Moreira, M. A.; Sci. Educ. 2002, 86, 106.

20. Allerhand, A.; Dobie-Galuska, A.; Chem. Educ. 2000, 6, 71.

21. Jones, R. B.; J. Chem. Educ. 2000, 77, 1085.

22. Lipkowitz, K. B.; Jalaie, M.; Robertson D.; Barth, A.; J. Chem. Educ. 1999, 76,684 
23. Tsai, C. S.; J. Chem. Educ. 2000, 77, 219.

24. Wilson, A.; Education in Chemistry 1996, September, 134.

25. Williamson, V. M.; Abraham, M. R.; J. Res. Sci. Teaching 1995, 32, 521.

26. Alibrandi, G.; D'Alberti, S.; Pedicini, R.; Chem. Educ. 2001, 7, 185.

27. Bampos, N.; Vidal-Ferran, A.; J. Chem. Educ. 2000, 77, 130.

28. Eaker, C. W.; Chem. Educ. 2000, 5, 1.

29. Garcia-Jareno, J. J.; Benito, D.; Vicente, F.; J. Chem. Educ. 2000, 77, 738

30. Habata, Y.; Akabori, S.; J. Chem. Educ. 2001, 78, 121.

31. Haddy, A. J.; Chem. Educ. 2001, 78, 1206.

32. Hyde, R. T.; Shaw, P. N.; Jackson, D. E.; Computers Educ. 1996, 26, 233.

33. Kozma, R. B. Educ. Technol. Res. Dev. 1994, 42, 11.
34. Mebane, R. C.; Schanley S. A.; Rybolt, T. R.; Bruce, C. D.; J. Chem. Educ. 1999, 76, 688

35. Pavlinic, S.; Buckley, P. D.; J. Chem. Educ. 2000, 77, 231.

36. Varneck, A. A.; Dietrich, B.; Wipff, G.; Lehn, J.; Boldyreva, E.; J. Chem. Educ. 2000, 77, 222.

37. Wolfskill, T.; Hanson, D.; J. Chem. Educ. 2001, 78, 1417.

38. Reid, K. L.; Wheatley, R. J.; Brudges, S. W.; Horton, J. C.; J. Chem. Educ. 2000, 77, 407 .

39. Whitelock, D.; Ensaio - Pesquisa em Educação e Ciências 2000, 2, 57.

40. White, B. Y.; Shimoda, T. A. e Frederiksen, J. R.; Int. J. Artificial Intelligence in Education 1999, 10, 151. 